\title{
Expression of transient receptor potential cation channel subfamily $M$ member 8 in gastric cancer and its clinical significance
}

\author{
QIQI XU，NA KONG，JUN ZHANG，NAN BAI，JINGTAO BI and WENDONG LI \\ Department of General Surgery, Beijing Jishuitan Hospital, Beijing 100035, P.R. China
}

Received January 19, 2020; Accepted June 2, 2020

DOI: $10.3892 /$ etm.2021.9808

\begin{abstract}
Transient receptor potential cation channel subfamily M member (TRPM8) is abnormally expressed in many malignant tumors, such as breast cancer and pancreatic cancer, but its expression in gastric cancer (GC) has remained unclear. The present study aimed to detect TRPM8 expression and to explore its clinical significance in GC. Western blotting and immunohistochemistry were used to detect the protein expression of TRPM8 in 134 pairs of GC and adjacent healthy tissues. The association of TRMP8 with the 5-year overall survival rate of patients with GC was assessed using a Cox regression model. TRPM8 protein expression was significantly elevated $(\mathrm{P}<0.05)$ in gastric tumor cells (SUN-1, AGS, SNU-5 and NCI-N87) and was significantly associated with tumor diameter $(\mathrm{P}=0.003)$, Tumor-Node-Metastasis stage $(\mathrm{P}=0.003)$, lymph node metastasis $(\mathrm{P}=0.001)$ and cancer cell remote metastasis $(\mathrm{P}=0.010)$ in patients with $\mathrm{GC}$. The expression of TRPM8 protein was significantly higher in GC patients with a tumor diameter of $\geq 2.5 \mathrm{~cm}$. Additionally, TRPM8 protein expression in patients with metastases was significantly higher compared with patients without metastasis. Cox regression analysis revealed that TRPM8 protein expression was an independent risk factor for prognosis (odds ratio, 1.625; 95\% $\mathrm{CI}=0.552-3.128$ ) in patients with GC. In addition, the 5 -year overall survival rate of patients with high expression of TRPM8 protein (64.44\%) in GC was significantly lower compared with patients with low expression (12.36\%). TRPM8 was highly expressed in GC tissues and may promote GC cell proliferation and metastasis in vivo.
\end{abstract}

\section{Introduction}

Gastric cancer (GC) is a malignant tumor originating from the gastric mucosa and is one of the malignant tumors of

Correspondence to: Dr Wendong Li, Department of General Surgery, Beijing Jishuitan Hospital, 31 East Street, Beijing 100035, P.R. China

E-mail: liwendmail@sina.com

Key words: transient receptor potential cation channel subfamily $\mathrm{M}$ member 8, TRPM8, gastric cancer, proliferation, metastasis the digestive tract that seriously endanger human health (1). Globally in 2012, $>70 \%$ of new cases of GC occur in developing countries and $50 \%$ of cases occur in eastern Asia of which the majority is seen in China (1). According to data released by the China Cancer Center in 2015, the number of new cases of patients with GC in China was 679,000 per year, second only to lung cancer $(733,000$ per year) (2). Notably, the detection rate of early GC is only $10 \%$ due to a lack of specific early clinical symptoms and diagnostic indicators $(3,4)$. Therefore, most patients with GC are diagnosed at an advanced stage and the 5-year survival rate is poor, with a 5-year overall survival rate of $20 \%$ for those treated only by surgery and $30-50 \%$ for those treated with surgery and adjuvant therapy (5). Therefore, the exploration of specific diagnostic and therapeutic targets is of considerable significance to develop targeted drugs and improve the survival of patients with GC.

The transient receptor potential cation channel subfamily $M$ member 8 (TRPM8) is a vital subtype of the transient receptor potential (TRP) and was first detected in prostate tissue (6). The human TRPM8 gene, which is located on chromosome $2 \mathrm{q} 37.1$, is composed of 25 exons, encodes a protein containing 1,104 amino acids, is mainly expressed on the cell membrane as a transmembrane protein and is known to be involved in perceiving temperature and pain $(7,8)$. As a cold-sensitive channel protein, TRPM8 can be activated by low temperatures $\left(27^{\circ} \mathrm{C}\right)(9)$. Previous studies have demonstrated that TRPM8 activation can cause $\mathrm{Ca}^{2+}$ influx into cells and trigger a series of biological effects, such as cell proliferation, differentiation and migration $(10,11)$. TRPM8 was later confirmed to be abnormally expressed in a number of cancers, including breast (12), prostate (13) and pancreatic cancer (14). Additionally, TRPM8 is not only involved in regulating the biological characteristics of tumor cells $(15,16)$ but also serves as a potential tumor treatment target (17). In addition, TRPM8 has also been found to be a receptor for menthol which is a widely used drug, including for antitumor treatments $(9,18)$. Li et al $(19)$ found that menthol increased the $\mathrm{Ca}^{2+}$ concentration in a human bladder cancer cell line by activating its receptor TRPM8 which reduced the mitochondrial membrane potential, caused mitochondrial depolarization, induced cell apoptosis and exerted antitumor effects.

However, the expression of TRPM8 protein and its clinical significance in GC remains unclear. The present study aimed to detect TRPM8 expression and to explore its 
clinical significance in GC. The findings revealed that TRPM8 protein was highly expressed in GC tissues and affected the proliferation and metastasis of GC cells. The present study demonstrates that TRPM8 may be a potential target for the treatment of GC.

\section{Materials and methods}

Patient ethics and characteristics. Tumor and adjacent healthy tissues ( $>5 \mathrm{~cm}$ from tumor tissue) were collected by surgery from 134 patients with GC between January and December 2013 in the Beijing Jishuitan Hospital (Beijing, China). The average age of patients was $60.65 \pm 12.38$ years and other clinical data are presented in Table I. Inclusion criteria for the present study were: i) Patients with GC without any treatment before surgery; ii) patients with complete information, such as age, sex, imaging examination, tumor-node-metastasis (TNM) stage; iii) patients with a complete 5-year follow-up record; and iv) patients without any other malignant tumor or other chronic infectious diseases (such as HIV, HBV, HCV). The exclusion criteria for the present study were: i) Loss to follow-up (Telephone interviews every quarter, for a period of 5 years) or death from another illness or accident; ii) pregnant or lactating women, as well as drug users; and iii) withdrawn from the study halfway. All GC patients who provided tissues were informed of the content of this study and signed informed consent. All protocols related to human tissue samples were reviewed and monitored by the Ethics Committee at the Beijing Jishuitan Hospital (Beijing, China).

Cell lines and culture. GES-1, SNU-1, AGS, SNU-5, and NCI-N87 were purchased from the American type culture collection (ATCC) and were cultured in DMEM medium (cat. no. 11965092; Gibco; Thermo Fisher Scientific Inc.) supplemented with $10 \%$ fetal bovine serum (cat. no. 16140071; Gibco; Thermo Fisher Scientific Inc.) at $37^{\circ} \mathrm{C}$ with $5 \% \mathrm{CO}_{2}$. GES-1 is a normal gastric epithelial cell line and all others are GC cell lines.

Western blotting. Total protein was extracted from cells using a RIPA lysate buffer (cat. no. R0010; Beijing Solarbio Science \& Technology Co., Ltd.). Tissues were first broken apart in liquid nitrogen in a twist bowl and then total protein was extracted from the cells. The concentration of total protein was detected using a BCA kit (cat. no. C503021; Sangon Biotech Co. Ltd.). Subsequently, $50 \mu \mathrm{g}$ of protein per lane was separated by $10 \%$ SDS-PAGE under a $90 \mathrm{~V}$ constant voltage. The proteins were transferred from the SDS-PAGE gel to PVDF membranes. Following blocking with $5 \%$ skimmed milk at room temperature for $1 \mathrm{~h}$ at room temperature, the membranes were incubated with primary antibody against TRPM8 (1:500; cat. no. ab3243; Abcam) overnight at $4^{\circ} \mathrm{C}$. Then Goat Anti-Rabbit IgG H\&L (HRP; 1:2,000; cat. no. ab6721; Abcam) was added at room temperature for $2 \mathrm{~h}$. After washing 3 times with phosphate-buffered saline-Tween-20, ECL solution (cat. no. WBKLS0100; Beijing Xinjingke Biotechnologies Co., Ltd.) was added for detection. $\beta$-actin was used as the loading control. ImageJ v1.8.0 (National Institute of Health) was used to analyze protein grey value.
Immunohistochemistry (IHC). TRPM8 protein expression was detected and scored by IHC as described in a previous study (20). In the present study, the primary antibody used was an anti-TRPM8 antibody (1:100; cat. no. ab3243; Abcam) and PBS buffer was used as a negative control. The primary antibody was incubated overnight at $4^{\circ} \mathrm{C}$ and Goat Anti-Rabbit IgG H\&L (HRP; 1:1,000, cat. no. ab6721; Abcam) as the secondary antibody was incubated at room temperature for $1 \mathrm{~h}$. The number of positive cells were counted using Leica TCS SP5 microscope (magnification, x200; Leica Microsystems, Inc.).

Statistical analysis. SPSS 20.0 (IBM Corp.) was used to analyze the data in the present study. Data in the current study was presented as the mean \pm standard deviation, and three repeats were used for the same measurement. Both paired and unpaired Student's t-tests and the $\chi^{2}$ test were used to compare the differences between 2 groups and one-way ANOVA with the post hoc Tukey's test was used to compare the differences between multiple groups. The log-rank (Mantel-Cox) test was used to compare the survival of patients with high and low TRPM8 expression. A Cox regression model was used to analyze factors affecting the survival of patients with GC. $\mathrm{P}<0.05$ was considered to indicate a statistically significant difference.

\section{Results}

Upregulation of TRPM8 protein expression in GC cells and tissues. Firstly, the expression of TRPM8 protein in human gastric mucosal epithelial cell (GES-1) and human GC cells (SNU-1, AGS, SNU-5, and NCI-N87) was assessed. The expression of TRPM8 protein in human GC cells was significantly higher compared with that in normal human gastric mucosal epithelial cells and the level in the NCI-N87 cell line was highest (Fig. 1A and B). Then, tumor and adjacent healthy tissues from a 134 patients with GC were measured by western blotting and IHC. The expression of TRPM8 protein in GC tissues was significantly higher compared with that noted in the normal adjacent healthy tissues (Fig. 1C and D). In addition, IHC demonstrated that TRPM8 protein was located at the cell membrane (Fig. 1E) and the IHC score of TRPM8 protein expression in GC tissues was significantly higher compared with that observed in the adjacent tissues (Fig. 1F).

Association of TRPM8 and clinicopathological features of patients with GC. Patients with GC $(\mathrm{n}=134)$ were divided into 2 groups based on the expression of TRPM8 protein detected using immunohistochemistry, a TRPM8 protein low expression group $(n=45)$ with an IHC score of $<4$ and a high expression group $(n=89)$ with an IHC score of $\geq 4$. As shown in Table I, expression of TRPM8 protein was not significantly associated with sex $(\mathrm{P}=0.863)$, age $(\mathrm{P}=0.737)$, histological grade $(\mathrm{P}=0.769)$ or tumor number $(\mathrm{P}=0.672)$. However, it was significantly associated with tumor diameter $(\mathrm{P}=0.003)$, TNM stage $(\mathrm{P}=0.003)$, lymph node metastasis $(\mathrm{P}=0.001)$ and remote metastasis $(\mathrm{P}=0.010)$.

TRPM8 protein expression in gastric tumors of variable sizes. Based on preoperative imaging examination, the largest diameter of tumor tissue was determined (median 
Table I. Association of TRMP8 protein expression and clinicopathological characteristics of patients with gastric cancer ( $\mathrm{n}=134)$.

\begin{tabular}{|c|c|c|c|c|c|}
\hline \multirow[b]{2}{*}{ Features } & \multirow[b]{2}{*}{ Number of patients } & \multicolumn{2}{|c|}{ TRPM8 expression } & \multirow[b]{2}{*}{$\chi^{2}$} & \multirow[b]{2}{*}{ P-value } \\
\hline & & Low & High & & \\
\hline Sex & & & & 0.030 & 0.863 \\
\hline Female & 94 & 32 & 62 & - & - \\
\hline Male & 40 & 13 & 27 & & \\
\hline Age (years) & & & & 0.113 & 0.737 \\
\hline$<60$ & 48 & 17 & 31 & - & - \\
\hline$\geq 60$ & 86 & 28 & 58 & & \\
\hline Tumor diameter (cm) & & & & 8.945 & 0.003 \\
\hline$<2.5$ & 65 & 30 & 35 & - & - \\
\hline$\geq 2.5$ & 69 & 15 & 54 & & \\
\hline Histological grade (43) & & & & 0.524 & 0.769 \\
\hline $\mathrm{I}$ & 37 & 14 & 23 & - & - \\
\hline II & 52 & 16 & 36 & & \\
\hline III & 45 & 16 & 29 & & \\
\hline Tumor number & & & & 0.179 & 0.672 \\
\hline Single & 74 & 26 & 48 & - & - \\
\hline Multiple & 60 & 19 & 41 & & \\
\hline TNM stage (44) & & & & 14.195 & 0.003 \\
\hline I & 14 & 8 & 6 & - & - \\
\hline II & 38 & 19 & 19 & & \\
\hline III & 49 & 13 & 36 & & \\
\hline IV & 33 & 5 & 28 & & \\
\hline Lymph node metastasis & & & & 10.269 & 0.001 \\
\hline Yes & 82 & 19 & 63 & & \\
\hline No & 52 & 26 & 26 & & \\
\hline Cancer cell remote metastasis & & & & 6.668 & 0.010 \\
\hline Yes & 33 & 5 & 28 & & \\
\hline No & 101 & 40 & 61 & & \\
\hline
\end{tabular}

TNM, tumor-node-metastases; TRMP8, transient receptor potential cation channel subfamily M member 8 .

diameter of gastric tissues $=2.5 \mathrm{~cm})$ and patients with $\mathrm{GC}$ $(\mathrm{n}=134)$ were divided into 2 groups: Tumor diameter $<2.5 \mathrm{~cm}$ $(\mathrm{n}=65)$ and tumor diameter $\geq 2.5 \mathrm{~cm}(\mathrm{n}=69)$. As presented in Fig. 2A, the relative expression levels of TRPM8 in gastric cancer tissues with tumor diameters of $0.5,1.5,3.8,4.7$ and $7.1 \mathrm{~cm}$ are $0.12,0.33,0.58,1.18$ and 1.42 , respectively. TRPM8 protein expression in the $<2.5 \mathrm{~cm}$ group was significantly less compared with that in the $\geq 2.5 \mathrm{~cm}$ group using western blotting (Fig. 2A and B). In addition, the differences in TRPM8 protein expression were detected using IHC in the 2 groups divided by tumor diameter. Similarly, as indicated by Fig. 2A, the IHC score of TRPM8 in gastric cancer tissues with tumor diameters of $0.5,1.5,4.7$ and $7.1 \mathrm{~cm}$ are $1,2,4$ and 6 , respectively. It was also indicated that the IHC score in the $<2.5 \mathrm{~cm}$ group was significantly lower compared with the $\geq 2.5 \mathrm{~cm}$ group (Fig. 2C and D).

TRPM8 protein expression and GC cell metastasis. Patients with GC $(\mathrm{n}=134)$ were divided into 2 groups based on whether they had metastasis (lymph node or remote metastasis) or not and then TRPM8 protein expression was compared in these 2 groups. A total of 82 GC patients exhibited cancer cell metastasis (metastasis group) and 52 patients exhibited no cancer cell metastasis (non-metastasis group). TRPM8 protein expression in tissues of patients who had metastases was significantly higher compared with those without metastases as detected by western blotting (Fig. 3A and B). This was confirmed in the subsequent IHC analysis. As presented in Fig. 3C, TRPM8 protein IHC scores of patients with GC without and with lymph node metastasis were 2 and 3, respectively; TRPM8 protein IHC scores of patients with GC without and with distant cancer cell metastasis were 4 and 6 , respectively. The IHC score of TRPM8 protein in patients with GC who had metastases was significantly elevated compared with those without metastases (Fig. 3C and D).

Association between TRPM8 protein expression and the prognosis of patients with $G C$. Patients with GC were followed up for 5 years after surgery to record the time of death and to compare 
A

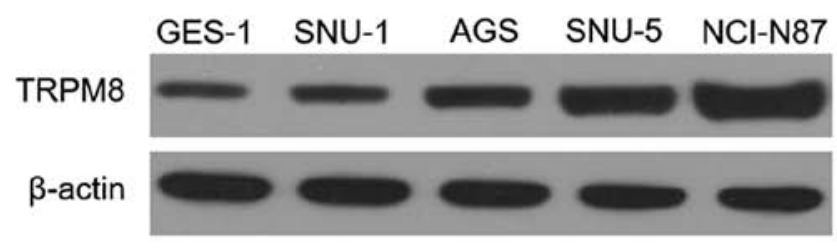

B

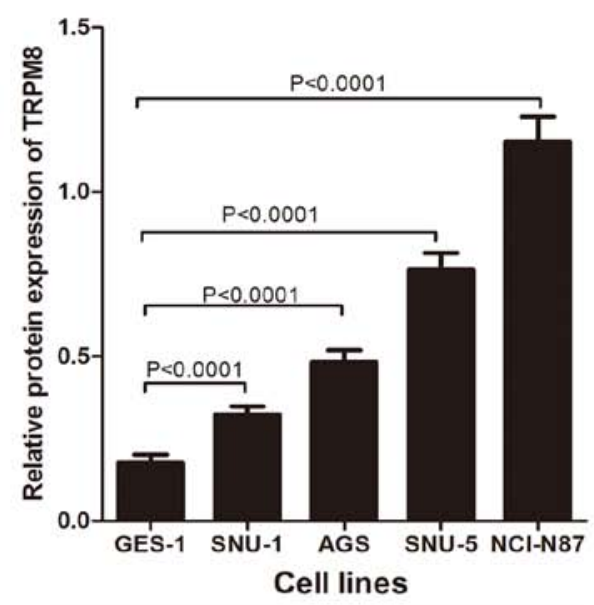

D

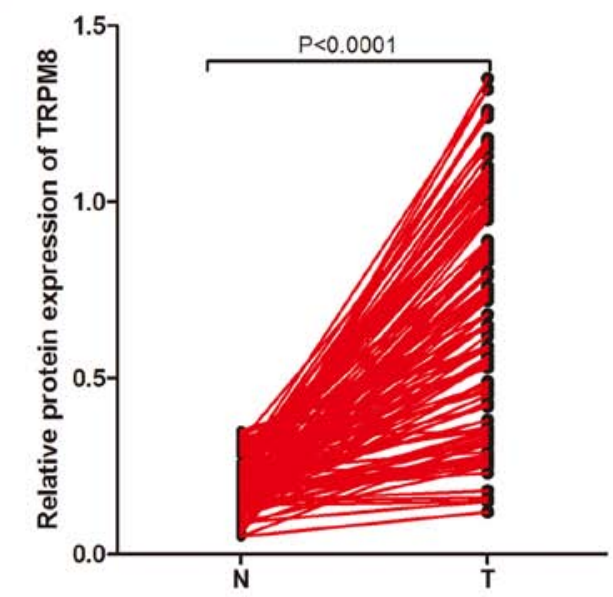

F

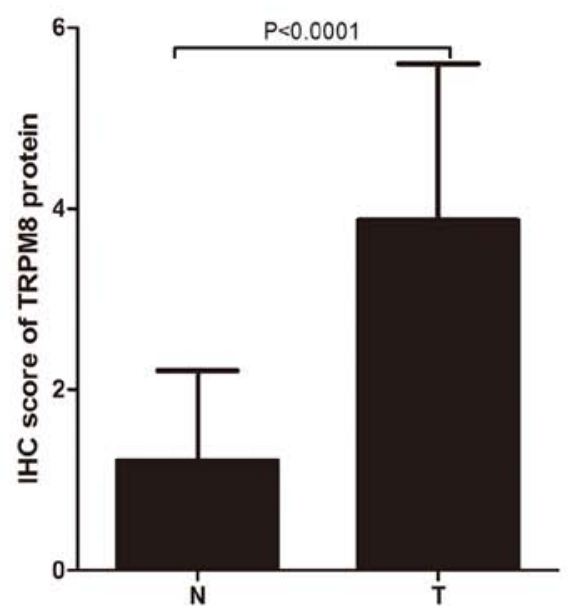

Figure 1. TRPM8 protein expression is elevated in GC cells and tissues. (A) Representative protein bands and (B) TRPM8 protein expression quantification in human gastric mucosal epithelial (GES-1) cells and human GC cells (SNU-1, AGS, SNU-5 and NCI-N87) using western blotting. (C and D) Western blotting was used to detect the expression of TRPM8 protein in normal and tumor tissues from patients with GC and (C) presents the protein bands and (D) the result obtained using a before-after connection graph. (E and F) TRPM8 IHC staining of normal and tumor tissues from patients with GC ( $\mathrm{n}=134)$ was performed and (E) presents the staining results from 2 patients with GC (x100) and (F) comparison of TRPM8 protein IHC scores between normal and tumor tissues. P-values were calculated using one-way ANOVA with the post hoc Tukey's test (B), but were calculated using a paired Student's t-test in (D) and (F). GC, gastric cancer; $\mathrm{N}$, normal tissue; T, tumor tissue; IHC, immunohistochemistry; TRMP8, transient receptor potential cation channel subfamily M member 8.

the 5-year overall survival rate of patients with different TRPM8 protein expression levels. A total of $64.44 \%$ (29/45) of patients with low TRPM8 protein expression were still alive 5 years after surgery, while only $12.36 \%$ (11/89) of patients with high TRPM8 protein expression levels were still alive (Fig. 4). The difference in 5-year survival of patients with variable TRPM8 protein expression levels was significant (Fig. 4). In addition, the influencing factors for survival were assessed using the Cox regression model. According to the results of univariate analysis, histological grade $(\mathrm{OR}=2.842 ; 95 \% \mathrm{CI}=2.342-3.210)$, 
A

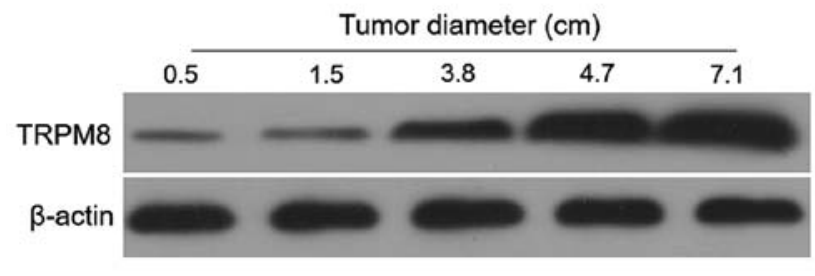

C
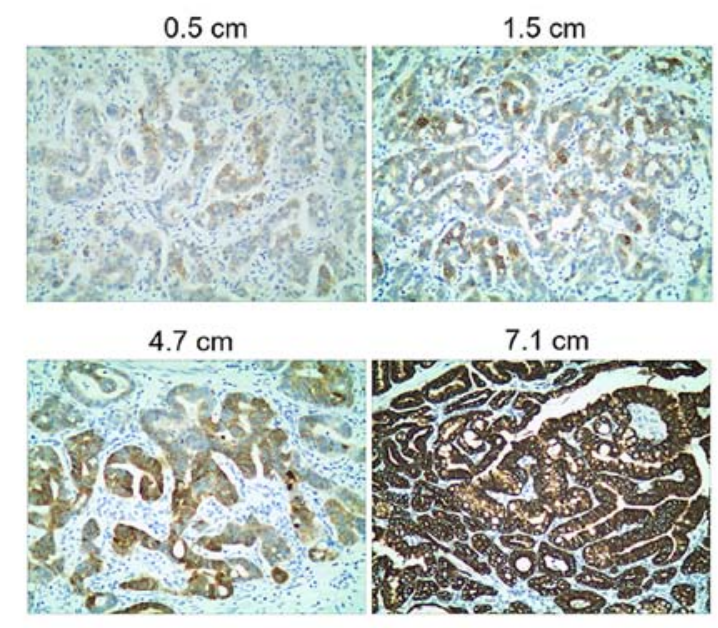

B

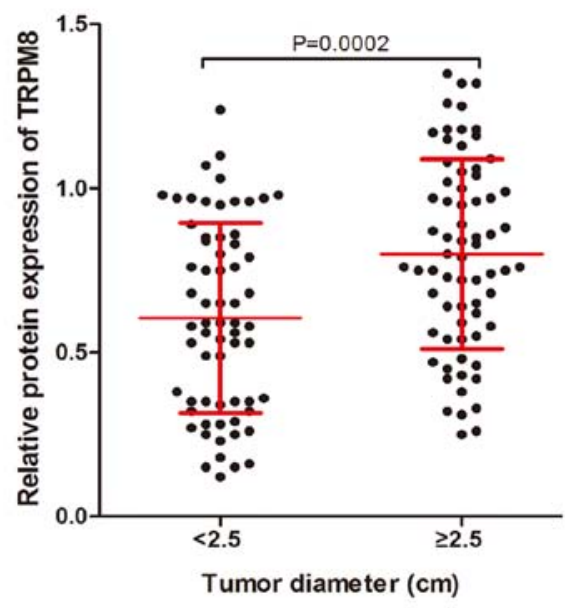

D

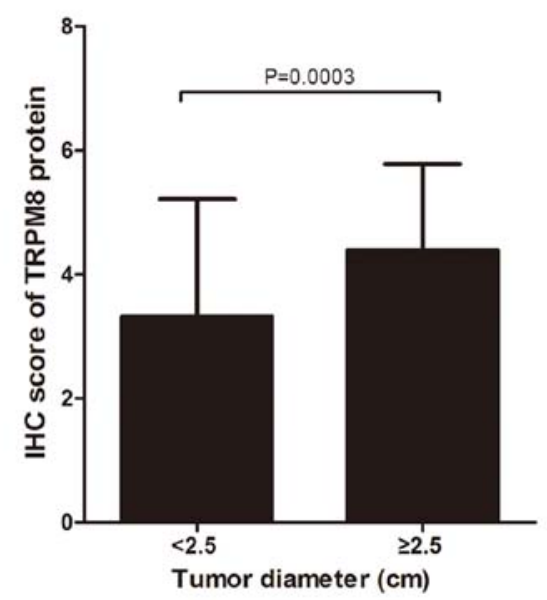

Figure 2. TRPM8 protein expression is related to tumor size of GC. (A) Representative protein bands of TRPM8 in different sizes of tumor tissues and (B) quantitative results of western blotting. (C and D) Representative Immunohistochemistry images of TRPM8 in different sizes of tumor tissues (x100) (C) and comparison of IHC score (D) in patients with GC with tumor sizes $<2.5 \mathrm{~cm}(\mathrm{n}=65)$ or $\geq 2.5 \mathrm{~cm}$ ( $\mathrm{n}=69)$. P-value was calculated using the unpaired Student's t-test in (B) and (D). GC, gastric cancer; IHC, immunohistochemistry; TRMP8, transient receptor potential cation channel subfamily M member 8.

TNM stage $(\mathrm{OR}=0.854 ; 95 \% \mathrm{CI}=0.328-1.264)$, lymph node metastasis $(\mathrm{OR}=1.964 ; 95 \% \mathrm{CI}=1.405-3.218)$, remote metastasis $(\mathrm{OR}=3.264 ; 95 \% \mathrm{CI}=2.501-4.448)$ and TRPM8 levels $(\mathrm{OR}=1.032 ; 95 \% \mathrm{CI}=0.846-2.371)$. Multivariate analysis was also performed and it was indicated that TNM stage [odds ratio $(\mathrm{OR})=2.032 ; 95 \% \mathrm{CI}=0.625-3.102$ ], lymph node metastasis $(\mathrm{OR}=3.516 ; 95 \% \mathrm{CI}=1.653-4.021)$, remote metastasis $(\mathrm{OR}=3.237 ; 95 \% \mathrm{CI}=1.354-4.021)$ and $\mathrm{TRPM} 8$ protein expression levels $(\mathrm{OR}=1.625 ; 95 \% \mathrm{CI}=0.552-3.128)$ were independent risk factors that affected the 5-year survival of patients with GC (Table II).

\section{Discussion}

TRPM8 was initially cloned as a prostate-specific protein and was found to be activated by cold stimulation and menthol in a heat-sensitive response (6). TRP family proteins are involved in the occurrence of various diseases, such as TRPM8 is the principal mediator of menthol-induced analgesia of acute and inflammatory pain (21), anti-hyperalgesic effects of a novel TRPM8 agonist in neuropathic rats $(22)$ and cancer $(23,24)$. Jiang et al (25) found that transient receptor potential cation channel subfamily V member 6 knockdown could inhibit the invasion and migration of cancer cells. Orfanelli et al (26) found that transient receptor potential cation channel subfamily $\mathbf{M}$ member 2 played an essential role in the regulation of biological functions of tumor cells, such as proliferation, invasion and migration.

In the present study, TRPM8 protein expression in human GC cells was significantly higher compared with that in human gastric mucosal epithelial cells, and was also elevated in human GC tissues compared with adjacent healthy tissues. Numerous studies have demonstrated that TRPM8 plays a vital role in the development of tumors, suggesting TRPM8 may serve as an oncogene affecting the progression of a number of types of malignant tumors. Overexpression of the cation-permeable channel TRPM8 in prostate cancers promoted cancer progression and menthol inhibited the proliferation of prostate cancer cells by inhibiting the expression of TRPM8 protein (16). Knowlton and McKemy (27) summarized the emerging role of TRPM8 in a variety of biological systems, including thermoregulation, cancer, bladder function, and asthma. Furthermore, Wang et al (15) found that knockdown of TRPM8 suppresses cancer malignancy and enhances epirubicin-induced apoptosis in human osteosarcoma cells. The findings of the present study revealed that TRPM8 was highly expressed in GC cells and tissues, hence it may be involved in the regulation of GC development as an oncogene. 
A

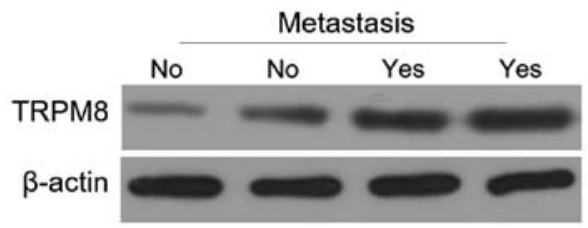

C

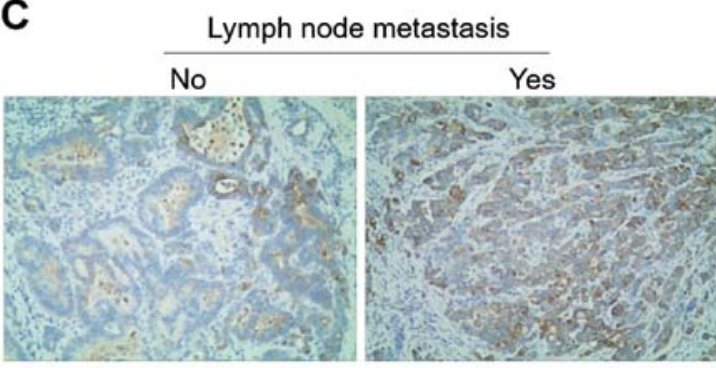

Cancer cells remote metastasis

No Yes

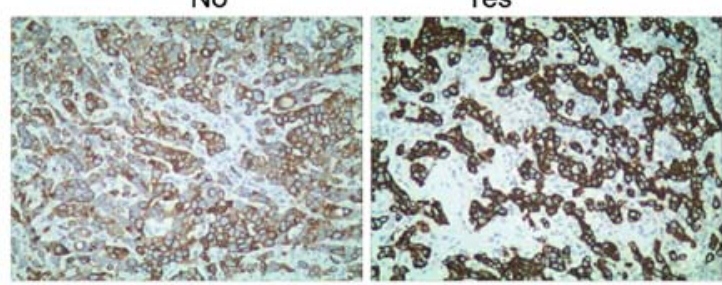

B

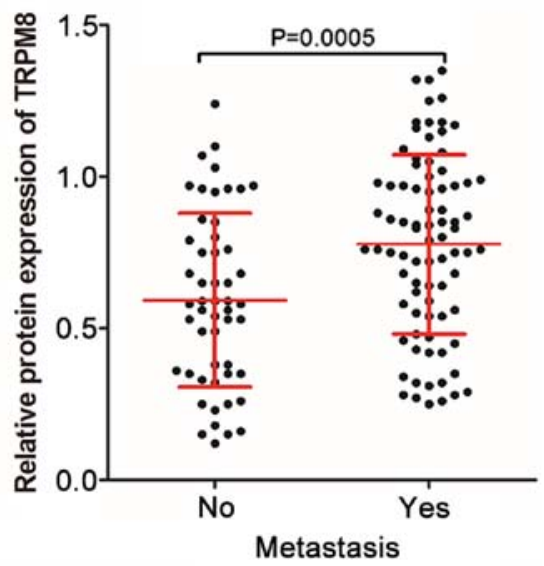

D

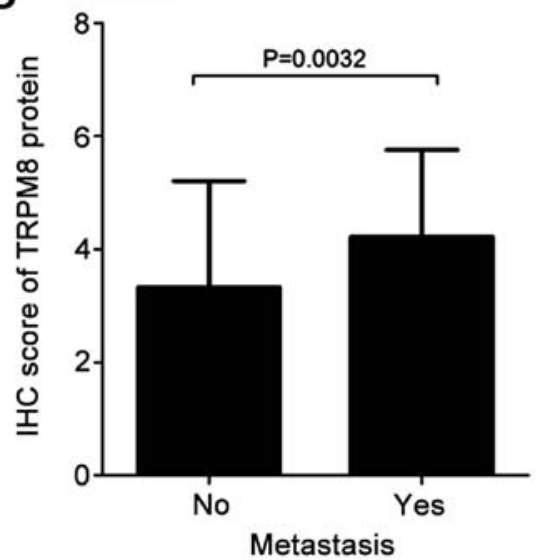

Figure 3. TRPM8 protein expression is associated with metastasis in patients with GC. Western blotting was used to detect the protein expression of TRPM8 in patients with GC with or without metastasis and (A) presents the protein bands and (B) quantitative data obtained. (C and D) Representative Immunohistochemistry pictures of TRPM8 in different sizes of tumor tissues (x100) (C) and comparison of IHC score (D) in patients with GC with ( $=82)$ or without $(n=52)$ metastasis. P-value was calculated by the Student's unpaired t-test in (B) and (D). GC, gastric cancer; IHC, immunohistochemistry; TRMP8, transient receptor potential cation channel subfamily $\mathrm{M}$ member 8.

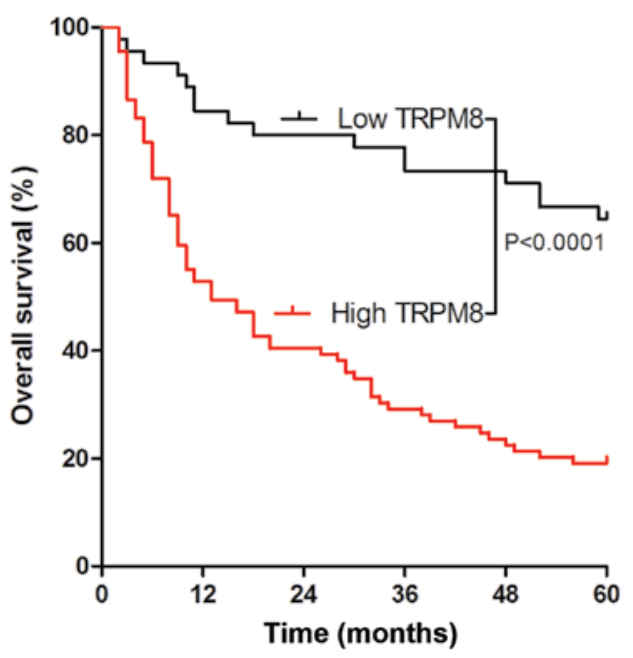

Figure 4. Effect of TRPM8 protein expression on 5-year overall survival of patients with GC. GC, gastric cancer; TRMP8, transient receptor potential cation channel subfamily M member 8.

In the present study, the association between TRPM8 protein expression and clinicopathological data from patients with GC was assessed and it was found that the expression of TRPM8 protein in GC tissues was significantly associated with the tumor diameter, TNM stage, lymph node metastasis and remote metastasis. Notably, in the present study TRPM8 protein was higher expressed in patients who had larger tumor diameters. The abnormal proliferation of tumor cells is the root cause of cancer and forms the basis for distinguishing them from normal cells (28). One of the functions of numerous antitumor drugs is the suppression of proliferation of tumor cells, including mechanisms that regulate cell cycle-related protein expression and mitochondrial toxicity $(15,29)$. TRPM8 has been found to be involved in promoting cell proliferation. Bidaux et al (30) found that the epidermal TRPM8 channel controls the balance between keratinocyte proliferation and differentiation in a cold-dependent manner and Yee (31) found that overexpression of TRPM8 is necessary for pancreatic cancer cell proliferation. On the other hand, TRPM8 has also been found to inhibit the proliferation of non-cancer cells and topical application of TRPM8 agonists can reduce epidermal proliferation induced by barrier insult in vivo (32) and inhibit the proliferative airway smooth muscle cell phenotype (33). In conclusion, these data indicate that TRPM8 is a cell proliferation-related protein.

The present study also found that the protein expression of TRPM8 in patients with GC who had metastases was significantly higher compared with patients without metastases. The characteristic that tumor cells are transferred from the primary site to other sites to continue to grow is not only a 
Table II. Analysis of factors that influence the overall survival of patients with gastric cancer $(n=134)$.

\begin{tabular}{lccccccc}
\hline & \multicolumn{3}{c}{ Univariate analysis } & & \multicolumn{3}{c}{ Multivariate analysis } \\
\cline { 2 - 3 } Features & $95 \% \mathrm{CI}$ & OR & P-value & & $95 \% \mathrm{CI}$ & OR & P-value \\
\hline Sex & $1.864-4.926$ & 3.021 & 0.089 & & - & - & - \\
Age & $0.792-2.657$ & 1.325 & 0.328 & & - & - & - \\
Tumor diameter & $1.358-4.328$ & 2.682 & 0.068 & & - & - & - \\
Histological grade & $1.969-3.427$ & 3.025 & $<0.001$ & & $1.129-3.641$ & 2.03 & 0.061 \\
Tumor number & $0.729-3.124$ & 1.682 & 0.062 & & - & - & - \\
TNM stage & $0.658-2.354$ & 1.382 & $<0.001$ & & $0.625-3.102$ & 2.032 & 0.001 \\
Lymph node metastasis & $1.223-3.512$ & 2.003 & $<0.001$ & & $1.653-4.021$ & 3.561 & 0.042 \\
Remote metastasis & $2.235-3.126$ & 2.658 & $<0.001$ & & $1.354-4.021$ & 3.237 & $<0.001$ \\
TRPM8 levels & $0.635-3.012$ & 1.324 & 0.012 & & $0.552-3.128$ & 1.625 & 0.028 \\
\hline
\end{tabular}

TNM, tumor-node-metastases; TRMP8, transient receptor potential cation channel subfamily M member 8; OR, odds ratio.

criterion for distinguishing between benign and malignant tumors, but also a major cause of treatment failure and death in patients with cancer (34). Numerous previous studies have found that upregulation of TRPM8 promotes metastasis. Okamoto et al (35) found that TRPM8 was highly expressed in oral squamous cell carcinomas and reducing the activity of TRPM8 could significantly decrease the activity of invasion in oral squamous carcinoma cells in vitro. TRPM8 has also been found to promote metastasis in lung and prostate cancer $(36,37)$. The results of the present study suggest that TRMP8 protein is a metastasis-related protein in GC.

In addition, the present study found that high expression of TRPM8 was associated with a poorer prognosis for patients with GC, this may be due to the promotion and proliferation of GC cells induced by TRPM8. Similarly, studies of TRPM8 expression in pancreatic cancer (38), urothelial carcinoma of the bladder (39) and osteosarcoma (40) also found that high expression of TRMP8 leads to poor prognosis. This indicates that TRMP8 could be used to evaluate the efficacy of treatment by comparing the expression level of TRPM8 in GC tumor tissue before and after treatment. In addition, since the TRPM8 protein expression is associated with the prognosis of patients with GC, modulating the expression of TRPM8 in patients with GC through treatment may affect the prognosis. In conclusion, TRPM8 may be a potential target for treatment or a parameter for tumor screening in GC. As TRPM8 is a menthol receptor, it has been used as a target for menthol-induced apoptosis of human bladder cancer cell line T24 (19) and human leukemia cell HL-60 (41). TRPM8 has been widely used in the development of drugs for the treatment of malignant tumors, such as menthol and cannabigerol $(10,42)$.

The present study had several limitations, no cell proliferation and metastatic assays were performed to investigate the effects of TRPM8 expression in GC cells. The findings of this study were based on in vivo data, functional in vitro mechanistic studies are required to verify the findings of the present study. In conclusion, the present study found that the TRPM8 protein was highly expressed in GC tissues and is associated with the development of GC and may promote GC cell proliferation and metastasis as an oncogene. The current study demonstrated that
TRPM8 is a potential target for the treatment of gastric cancer, and some drugs used to treat cancer that target TRPM8 can be used for the treatment of gastric cancer.

\section{Acknowledgements}

Not applicable.

\section{Funding}

This study was supported by a grant from Beijing JST Research Funding (grant no. ZR-201919).

\section{Availability of data and materials}

All data generated or analyzed during the present study are included in this published article.

\section{Authors' contributions}

WL was responsible for the conception and design of the study. QX drafted the manuscript and revised the final draft for important intellectual content; QX, NK, JZ, NB and JB performed the experiments and analyzed the data. All authors have read and approved the manuscript.

\section{Ethics approval and consent to participate}

This study was performed with the approval of the Ethics Committee of Beijing Jishuitan Hospital (Beijing, China). All aspects of the study complied with the Declaration of Helsinki. All patients provided written informed consent.

\section{Patient consent for publication}

Not applicable.

\section{Competing interests}

The authors declare that they have no competing interests. 


\section{References}

1. Ferlay J, Soerjomataram I, Dikshit R, Eser S, Mathers C, Rebelo M, Parkin DM, Forman D and Bray F: Cancer incidence and mortality worldwide: Sources, methods and major patterns in GLOBOCAN 2012. Int J Cancer 136: E359-E386, 2015.

2. Chen W, Zheng R, Baade PD, Zhang S, Zeng H, Bray F, Jemal A, $\mathrm{Yu}$ XQ and He J: Cancer statistics in China, 2015. CA Cancer J Clin 66: 115-132, 2016.

3. Shiraishi N, Yasuda K and Kitano S: Laparoscopic gastrectomy with lymph node dissection for gastric cancer. Gastric Cancer 9 : 167-176, 2006.

4. Jackson C, Cunningham D and Oliveira J; ESMO Guidelines Working Group: Gastric cancer: ESMO clinical recommendations for diagnosis, treatment and follow-up. Ann Oncol 20 (Suppl 4): S34-S36, 2009

5. Jiang L, Yang KH, Guan QL, Chen Y,Zhao P and Tian JH: Survival benefit of neoadjuvant chemotherapy for resectable cancer of the gastric and gastroesophageal junction: A meta-analysis. J Clin Gastroenterol 49: 387-394, 2015.

6. Tsavaler L, Shapero MH, Morkowski S and Laus R: Trp-p8, a novel prostate-specific gene, is up-regulated in prostate cancer and other malignancies and shares high homology with transient receptor potential calcium channel proteins. Cancer Res 61 : 3760-3769, 2001

7. Liu SC, Lu HH, Cheng LH, Chu YH, Lee FP, Wu CC and Wang HW: Identification of the cold receptor TRPM8 in the nasal mucosa. Am J Rhinol Allergy 29: e112-e116, 2015.

8. Borowiec AS, Sion B, Chalmel F, D Rolland A, Lemonnier L, De Clerck T, Bokhobza A, Derouiche S, Dewailly E, Slomianny C, et al: Cold/menthol TRPM8 receptors initiate the cold-shock response and protect germ cells from cold-shock-induced oxidation. FASEB J 30: 3155-3170, 2016.

9. Bautista DM, Siemens J, Glazer JM, Tsuruda PR, Basbaum AI, Stucky CL, Jordt SE and Julius D: The menthol receptor TRPM8 is the principal detector of environmental cold. Nature 448: 204-208, 2007.

10. Yudin Y and Rohacs T: Regulation of TRPM8 channel activity. Mol Cell Endocrinol 353: 68-74, 2012.

11. Yamamura H, Ugawa S, Ueda T, Morita A and Shimada S: TRPM8 activation suppresses cellular viability in human melanoma. Am J Physiol Cell Physiol 295: C296-C301, 2008.

12. Chodon D, Guilbert A, Dhennin-Duthille I, Gautier M, Telliez MS, Sevestre H and Ouadid-Ahidouch H: Estrogen regulation of TRPM8 expression in breast cancer cells. BMC Cancer 10: 212, 2010.

13. Shan Y, Xu Z, Chang Z, Wu D, Wang Y, Yao X, Ng CF and Chan FL: Ion channel TRPM8 promotes hypoxic growth of prostate cancer cells via an O2-independent and RACK1-mediated mechanism of HIF-1 $\alpha$ stabilization. J Pathol 234: 514-525, 2014.

14. Yee NS, Chan AS, Yee JD and Yee RK: TRPM7 and TRPM8 ion channels in pancreatic adenocarcinoma: Potential roles as cancer biomarkers and targets. Scientifica (Cairo) 2012: 415158, 2012.

15. Wang Y, Yang Z, Meng Z, Cao H, Zhu G, Liu T and Wang X Knockdown of TRPM8 suppresses cancer malignancy and enhances epirubicin-induced apoptosis in human osteosarcoma cells. Int J Biol Sci 10: 90-102, 2013.

16. Valero ML, Mello de Queiroz F, Stühmer W, Viana F and Pardo LA: TRPM8 ion channels differentially modulate proliferation and cell cycle distribution of normal and cancer prostate cells. PLoS One 7: e51825, 2012.

17. Liu Z, Wu H, Wei Z, Wang X, Shen P, Wang S, Wang A, Chen W and Lu Y: TRPM8: A potential target for cancer treatment. J Cancer Res Clin Oncol 142: 1871-1881, 2016.

18. Namer B, Seifert F, Handwerker HO and Maihöfner C: TRPA1 and TRPM8 activation in humans: Effects of cinnamaldehyde and menthol. Neuroreport 16: 955-959, 2005.

19. Li Q, Wang X, Yang Z, Wang B and Li S: Menthol induces cell death via the TRPM8 channel in the human bladder cancer cell line T24. Oncology 77: 335-341, 2009.

20. Shimada K, Uzawa K, Kato M, Endo Y, Shiiba M, Bukawa H, Yokoe $\mathrm{H}$, Seki N and Tanzawa H: Aberrant expression of RAB1A in human tongue cancer. Br J Cancer 92: 1915-1921, 2005.

21. Liu B, Fan L, Balakrishna S, Sui A, Morris JB and Jordt SE: TRPM8 is the principal mediator of menthol-induced analgesia of acute and inflammatory pain. Pain 154: 2169-2177, 2013.
22. Patel R, Gonçalves L, Leveridge M, Mack SR, Hendrick A, Brice NL and Dickenson AH: Anti-hyperalgesic effects of a novel TRPM8 agonist in neuropathic rats: A comparison with topical menthol. Pain 155: 2097-2107, 2014.

23. Bödding M: TRP proteins and cancer. Cell Signal 19: 617-624, 2007.

24. Shapovalov G, Ritaine A, Skryma R and Prevarskaya N: Role of TRP ion channels in cancer and tumorigenesis. Semin Immunopathol 38: 357-369, 2016.

25. Jiang Y, Gou H, Zhu J, Tian S and Yu L: Lidocaine inhibits the invasion and migration of TRPV6-expressing cancer cells by TRPV6 downregulation. Oncol Lett 12: 1164-1170, 2016.

26. Orfanelli U, Wenke AK, Doglioni C, Russo V, Bosserhoff AK and Lavorgna G: Identification of novel sense and antisense transcription at the TRPM2 locus in cancer. Cell Res 18: 1128-1140, 2008.

27. Knowlton WM and McKemy DD: TRPM8: From cold to cancer, peppermint to pain. Curr Pharm Biotechnol 12: 68-77, 2011.

28. Evan GI and Vousden KH: Proliferation, cell cycle and apoptosis in cancer. Nature 411: 342-348, 2001.

29. Colston KW, Berger U and Coombes RC: Possible role for vitamin D in controlling breast cancer cell proliferation. Lancet 333: 188-191, 1989.

30. Bidaux G, Borowiec AS, Gordienko D, Beck B, Shapovalov GG, Lemonnier L, Flourakis M, Vandenberghe M, Slomianny C, Dewailly E, et al: Epidermal TRPM8 channel isoform controls the balance between keratinocyte proliferation and differentiation in a cold-dependent manner. Proc Natl Acad Sci USA 112: E3345-E3354, 2015.

31. Yee NS: Roles of TRPM8 Ion channels in cancer: Proliferation, survival, and invasion. Cancers (Basel) 7: 2134-2146, 2015.

32. Denda M, Tsutsumi M and Denda S: Topical application of TRPM8 agonists accelerates skin permeability barrier recovery and reduces epidermal proliferation induced by barrier insult: Role of cold-sensitive TRP receptors in epidermal permeability barrier homoeostasis. Exp Dermatol 19: 791-795, 2010.

33. Zhang L, An X, Wang Q and He M: Activation of cold-sensitive channels TRPM8 and TRPA1 inhibits the proliferative airway smooth muscle cell phenotype. Lung 194: 595-603, 2016.

34. Brooks SA, Lomax-Browne HJ, Carter TM, Kinch CE and Hall DM: Molecular interactions in cancer cell metastasis. Acta Histochem 112: 3-25, 2010.

35. Okamoto Y, Ohkubo T, Ikebe T and Yamazaki J: Blockade of TRPM8 activity reduces the invasion potential of oral squamous carcinoma cell lines. Int J Oncol 40: 1431-1440, 2012.

36. Du GJ, Li JH, Liu WJ, Liu YH, Zhao B, Li HR, Hou XD, Li H, Qi XX and Duan YJ: The combination of TRPM8 and TRPA1 expression causes an invasive phenotype in lung cancer. Tumour Biol 35: 1251-1261, 2014.

37. Yang ZH, Wang XH, Wang HP and Hu LQ: Effects of TRPM8 on the proliferation and motility of prostate cancer PC-3 cells. Asian J Androl 11: 157-165, 2009.

38. Du JD, Zheng X, Chen YL, Huang ZQ, Cai SW, Jiao HB, Zhu ZM and Hu B: Elevated transient receptor potential melastatin 8 (TRPM8) expression is correlated with poor prognosis in pancreatic cancer. Med Sci Monit 24: 3720-3725, 2018.

39. Xiao N, Jiang LM, Ge B, Zhang TY, Zhao XK and Zhou X: Over-expression of TRPM8 is associated with poor prognosis in urothelial carcinoma of bladder. Tumour Biol 35: 11499-11504, 2014.

40. Zhao $\mathrm{W}$ and $\mathrm{Xu} \mathrm{H}$ : High expression of TRPM8 predicts poor prognosis in patients with osteosarcoma. Oncol Lett 12: 1373-1379, 2016.

41. Lu HF, Hsueh SC, Yu FS, Yang JS, Tang NY, Chen SC and Chung JG: The role of $\mathrm{Ca} 2+$ in (-)-menthol-induced human promyelocytic leukemia HL-60 cell death. In Vivo 20: 69-75, 2006.

42. Bhatia SP, Mcginty D, Letizia CS and Api AM: Fragrance material review on 1-menthol. Food Chem Toxicol 46 (Suppl 11): S224-S227, 2008.

This work is licensed under a Creative Commons Attribution-NonCommercial-NoDerivatives 4.0 International (CC BY-NC-ND 4.0) License. 